\section{Vascular anomalies in the mesenteric circulation of patients with Crohn's disease: a pilot study}

\author{
Matilde Zamboni, ${ }^{1}$ \\ Maria Grazia Sibilla, ${ }^{2}$ \\ Roberto Galeotti, ${ }^{3}$ Massimo Pedriali, ${ }^{4}$ \\ Simona Ascanelli ${ }^{2}$ \\ ${ }^{1}$ Department of Thoracic, Cardiac, and \\ Vascular Sciences, Post Graduated \\ School in Vascular Surgery, University \\ of Padua; ${ }^{2}$ Department of Surgery, Unit \\ of Translational Surgery, University- \\ Hospital of Ferrara; ${ }^{3}$ Unit of Vascular \\ and Interventional Radiology, \\ University-Hospital of Ferrara; ${ }^{4}$ Unit of \\ Anatomy, Histology and Pathological \\ Citology, University-Hospital of Ferrara, \\ Italy
}

\begin{abstract}
Crohn's disease (CD) is a chronic inflammatory bowel disease and its pathogenesis is still not well understood. Previous studies suggested the possibility of the involvement of vascular system, but, todate, the mesenteric circulation has poor been investigated, especially in complicated $\mathrm{CD}$ cases requiring colectomy.

We investigated the mesenteric circulation in a case-control pilot study, including 19 controls and 7 patients affected by complicated cases of CD. Cases and controls underwent selective angiography of both superior and inferior mesenteric district.

Transit time was found either significantly shortened in $2 / 7$ cases $(29 \%)$, or prolonged 5/7 (71\%) $(\mathrm{P}=0.0034$ in the superior mesenteric district; $\mathrm{P}=0.0079$ in the inferior mesenteric district), respectively due to the presence of $\mathrm{A}-\mathrm{V}$ malformations and of a miscellaneous of venous abnormalities, which included thrombosis, hypoplasia and extra-truncular venous malformations.

Our study demonstrates the presence of congenital or acquired vascular anomalies in a small sample of CD patients not responder to current treatment and with severe complications. The present pilot study warrants further investigations.
\end{abstract}

\section{Introduction}

Crohn's disease (CD) is an inflammatory bowel disease and its pathogenesis is still unknown.
So many have been the hypothesis: viral and bacterial infections, hereditary factors, disregulation of the immunitary system, enviromental factors etc. ${ }^{1-6}$

$\mathrm{CD}$ is clinically characterized by both bowel and extrabowel symptoms. The first are abdominal pain, diarrhea, meteorism, loss of weight, anorexia; the second and less frequent are tipically rheumatological: erythema nodosum, pyodherma gangrenosum, anklylosing spondylitis, arthropathy, uveitis, episcleritis. ${ }^{1}$

In the majority part of the population $\mathrm{CD}$ does not remain steady but it progresses into a serious of dramatic and surgical situations such as bowel obstruction/perforation, recurrent fistulas (enterocutaneous, enteroenteric, enterocolic, enterovaginal) which affect on the quality of life of this population. ${ }^{1-6}$ Old and recent studies seems to indicate the possible involvement of the vascular system in the pathogenesis of the disease. ${ }^{6-12}$ The first big chapter concernes deep venous thrombosis (DVT). During years it has been noticed and confirmed that DVT is highly increased in CD (2-4 times more respect to healthy controls). ${ }^{10}$ This phenomenon could be explained by a series of organic situations which are usually present in CD patients: systemic inflammatory, loss of water, stillness, surgery, steroid therapy. ${ }^{8-10}$

The second chapter looks after vascular abnormalities and CD. There are just a few studies conducted in the 70's by some Swedish groups. They investigated celiac and mesenteric arteries with angiographies and demonstrated that the majority part (90\%) of population with CD or ulcerative colitis exhibited different angiographic anomalies. ${ }^{11-12}$

We hypothesized that an aggressive CD clinical course could be related to acquired and/or congenital mesenteric circulation pathology. Aim of the present study was to investigate patients with aggressive and complicated clinical course of CD studying selective angiographies of the mesenteric circulation.

\section{Ethical approval}

Our study is a pilot case-control study, approved by our Ethical Committee and registered at number $\# 140686$. All procedures performed were in accordance with the ethical standards of the institutional and/or national research committee and with the 1964 Helsinki declaration and its later amendments or comparable ethical standards.

Informed consent was obtained from all individual participants included in the study.
Correspondence: Matilde Zamboni, Department of Thoracic, Cardiac, and Vascular Sciences, Post Graduated School in Vascular Surgery, University of Padua, Italy. E-mail: wambazamba@icloud.com

Key words: Crohn's disease; mesenteric circulation; angiography; AV malformations.

Conflict of interest: the authors declare no conflict of interest.

Received for publication: 25 May 2017.

Revision received: 13 July 2017.

Accepted for publication: 14 July 2017.

This work is licensed under a Creative Commons Attribution 4.0 License (by-nc 4.0).

CC Copyright M. Zamboni et al., 2017

Licensee PAGEPress, Italy

Veins and Lymphatics 2017; 6:6817

doi:10.4081/vl.2017.6817

\section{Materials and Methods}

\section{Patient populations}

The control population was selected from 109 patients who underwent a mesenteric angiography in the last 5 years and none was affected by CD. Selection was based on the availability of a complete superior and inferior mesenteric study, with both arterial inflow and venous outflow, until the opacification of the portal trunk. The final control population was consisted of 19 patients, 12 males and 7 females and the reason why they underwent angiography includes a miscellaneous of digestive pathology (9 tumors, 2 visceral artery aneurysms, 4 bleedings, 2 angina abdominis, 1 vasculitis).

The case patients were $7 \mathrm{CD}$ patients with one or more complications mentioned before. They were 5 men and 2 women with an average age of 45 years old. They all underwent to a selective angiography study.

They were all acquainted about the procedure with risks and benefits and they all signed an informed consent. Case population and its demographic characteristics are shown in Table 1.

\section{Selective catheter angiography}

Standard angiography was performed selectively to show mesenteric arteries, superior and inferior, and their outflows.

Angiography was performed by a pretreatment with one butylscopolamine vial i.v. followed by Seldinger's technique and record of both arterial and venous time. We used a 5 French introducer and a Cobra 
catheter to study superior mesenteric district $(25-30 \mathrm{~mL}$ at a flow rate equal to 3 $\mathrm{mL} / \mathrm{sec}$ ) and a Simmons catheter for the inferior one $(15-20 \mathrm{~mL}$ at a flow rate equal to $2 \mathrm{~mL} / \mathrm{sec})$.

The iodinated contrast medium concentration was equally $400 \mathrm{mgI} / \mathrm{mL}$.

We studied angiographies in both cases and controls, specially we looked after the vascular morphology and the transit time (TT) evaluation. TT was calculated from the beginning of the automated injection until the portal vein appeared opacified by the contrast dye.

In one case we performed a selective angiography on the resected sigma soon after the surgical procedure.

\section{Statistical analysis}

Data were summarized as mean \pm standard deviation (SD).

Ordinary ANOVA Test was used to estimate TT; two sided Fischer Exact Test was used to estimate differences in the frequency of vascular abnormalities in both populations. Statistical significance was set with $\mathrm{p}<0.05$.

\section{Results}

Firstly TT was evaluated in the control population: $12.5 \pm 0.9 \mathrm{sec}$ in the superior mesenteric circulation and $17.9 \pm 1.4 \mathrm{sec}$ in the inferior one.

This functional result permitted to compare the mesenteric circulation in complicated $\mathrm{CD}$ respect to controls. Comparing TT results and angiography morphology we noticed that every CD patient had an altered TT accompanied by a vascular anomaly.

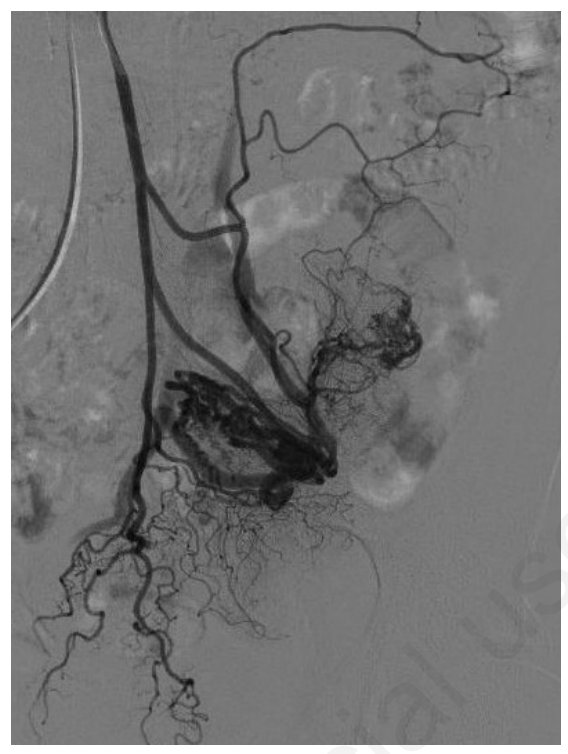

Figure 1. AV malformation.
Cases with AV malformation/fistulas

In case \#2 we documented an A-V malformation (AVM) by the means of selective angiography of the inferior mesenteric artery at the level of the superior haemorrhoidal artery (Figure 1). The patient clinically presented multiple not healing digestive fistulas, topographically corresponding to the bowel segment with low perfu-

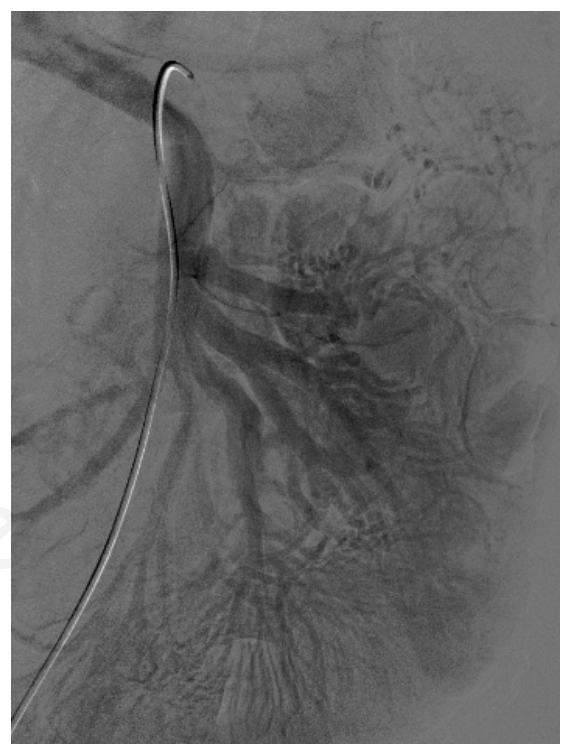

Figure 2. Extratroncular AV fistulas.

Table 1. Patients' cohort demographics and clinical characteristics.

\begin{tabular}{|c|c|c|c|c|c|c|c|c|c|}
\hline Patients & Age & $\mathrm{M} / \mathrm{F}$ & Smoke & Time to disease & Site of disease & $\begin{array}{c}\text { Bowel } \\
\text { complication }\end{array}$ & $\begin{array}{l}\text { Anorectal } \\
\text { complication }\end{array}$ & Surgery & Therapies \\
\hline L.Z. & 55 & M & Yes & 22 yrs & Ileum Colon & Obstruction & $\begin{array}{c}\text { Fistulas } \\
\text { Abscess }\end{array}$ & 3 & Metronidazole \\
\hline C.D. & 60 & M & Yes & $17 \mathrm{yrs}$ & Colon & Obstruction & $\begin{array}{l}\text { Fistulas } \\
\text { Abscess }\end{array}$ & 2 & Mesalazine \\
\hline F.M. & 55 & $\mathrm{~F}$ & Yes & $14 \mathrm{yrs}$ & $\begin{array}{l}\text { Jejunum } \\
\text { Ileum }\end{array}$ & Obstruction & $\begin{array}{l}\text { Fistulas } \\
\text { Abscess }\end{array}$ & 3 & Infliximab \\
\hline N.M. & 32 & $\mathrm{~F}$ & Yes & 7 yrs & $\begin{array}{l}\text { Ileum } \\
\text { Colon }\end{array}$ & Perforation & Abscess & 2 & Steroids \\
\hline D.M. & 48 & M & Yes & 24 yrs & $\begin{array}{l}\text { Ileum } \\
\text { Colon }\end{array}$ & Obstruction & Fistulas & 1 & None \\
\hline C.R. & 62 & M & Yes & $10 \mathrm{yrs}$ & Colon & Perforation & No & 1 & Steroids \\
\hline P.M. & 46 & M & Yes & $22 \mathrm{yrs}$ & $\begin{array}{l}\text { Ileum } \\
\text { Colon }\end{array}$ & Perforation & No & 2 & None \\
\hline
\end{tabular}

Table 2. Transit time evaluation, mean and standard deviation, in the superior and inferior mesenteric district. 
sion due to the A-V shunt. TT was reduced in the inferior mesenteric artery: $5 \mathrm{sec}$. The preoperative angiographic assessment permitted to regulate the margins of bowel resection. The relative bowel ischemia is well apparent in the post-operative selective angiography of the operatory specimen.

In case \#5 catheter arteriography of the superior mesenteric artery demonstrated the presence of multiple extratroncular AV fistulas (Figure 2) with an evident overload of the iliac veins, which appeared abnormally dilated. CD lesions corresponded to the intestinal areas of relative ischemia. Also in case \#5 TT was decreased (11 sec.) in the superior mesenteric district.

So, in these two AV shunt cases TT was significantly shorter: $10.5 \pm 0.7$ in the superior district and $8.5 \pm 4.9$ in the inferior one.

\section{Cases with prolonged mesenteric transit time}

In case $\# 1, \# 3, \# 4, \# 6, \# 7$ TT was significantly increased: $14.8 \pm 3 \mathrm{sec}$ in the superior mesenteric district and $22 \pm 4.8 \mathrm{sec}$ in the inferior one.

The reason of a slower circulation was represented by a series of venous anomalies: in case \#2 and in case \#7 we observed small sized mesenteric and/or iliac veins compatible with venous hypoplasia (Figure 3); dysplasia and varicosities of the parietal veins, compatible with extra-troncular venous malformation, were observed in case \#3 and \#4; and finally a mesenteric DVT was detected in case \#6 (Figure 4).

Overall TT was significantly different in the $C D$ population: $\mathrm{P}=0.0034$ in the superior district and $\mathrm{P}=0.0079$ in the inferior one (TT are shown in Table 2).

Finally, the presence of anomalies in the mesenteric circulation was significantly higher in complicated $\mathrm{CD}$ respect to controls $\quad(\mathrm{OR}=25, \quad 95 \% \quad$ CI $1.2-504$; $\mathrm{P}=0.0064$ ).

\section{Discussion}

The original idea of this study has been to observe bowel from a circulatory point of view. Indication to vascular study was given by the treating physician to understand more about the continuous development of severe complications in this group of patients. We have found a set of vascular anomalies and malformations, which are frequently observed in other districts of the human body. Particularly, out of the case of mesenteric DVT, the other six cases, according to a recent consensus statement, can be classified among the venous malformations. ${ }^{13}$

The IUP Classification divides the vascular malformations according to the flow rate and the stage of the vascular system development. In our survey we found two cases of high flow malformations and 5 of low flow rate. The latter could be extratruncular, whether the arrest of the development happens during the first three months of pregnancy, and truncular whether it occurs in later stages $\left(5^{\text {th }}-7^{\text {th }}\right.$ months). ${ }^{13}$

Both arterial and venous side were involved, potentially contributing to the patho-physiology of the disease: hypoperfusion, venous stasis, oedema and inflammation.

The second exclusive finding has been to calculate TT in both populations and find them significantly changed. This result reflects a pathological vascularization of bowel tissues and, possibly, a vascular contribution to the pathogenesis. For instance, the case of the AVM clinically corresponded to multiple not healing digestive fistulas, topographically in the bowel segment with low perfusion due to the shunt. The relative bowel ischemia is well apparent in the post-operative selective angiography of the operatory specimen (Figure 5). Moreover, cases with venous hypoplasia and/or venous thrombosis corresponded to biopsy where histology documented oedema and chronic inflammation.

Limitations of this preliminary study are the followings: i) angiographies in the control population have been performed mostly in bleeding patients, so TT could be distorted by haemodynamic adaptations of the body (blood loss and autonomic nervous system disregulation); ii) CD patients were complicated patients, which means people who underwent a bowel resection. This fact is so important because it means that angiographies do not show completely the original vascularization; iii) we do not have a TT evaluation in healthy CD patients without complications; iv) a small casuistry.

Furthermore, our data cannot clarify whether the vascular condition is a cause or a product of the bowel disease. However, our findings and results are very impressive and need to be amplified in a structured and wider case control study, including complicated patients before bowel resection.

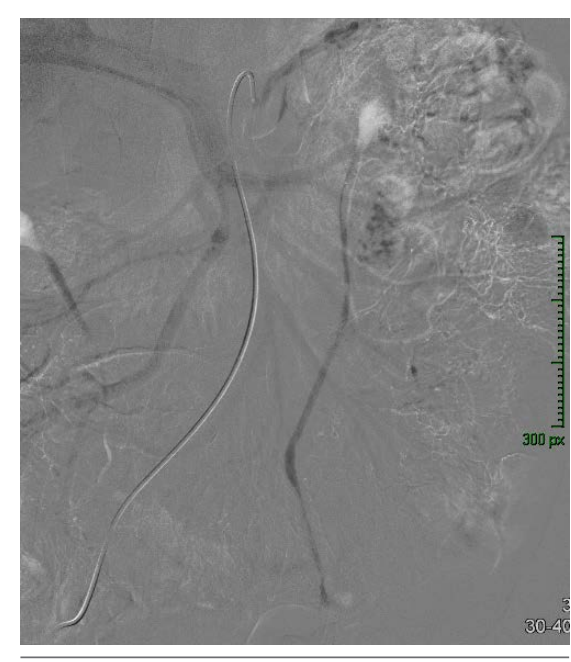

Figure 3. Troncular venous malformation.

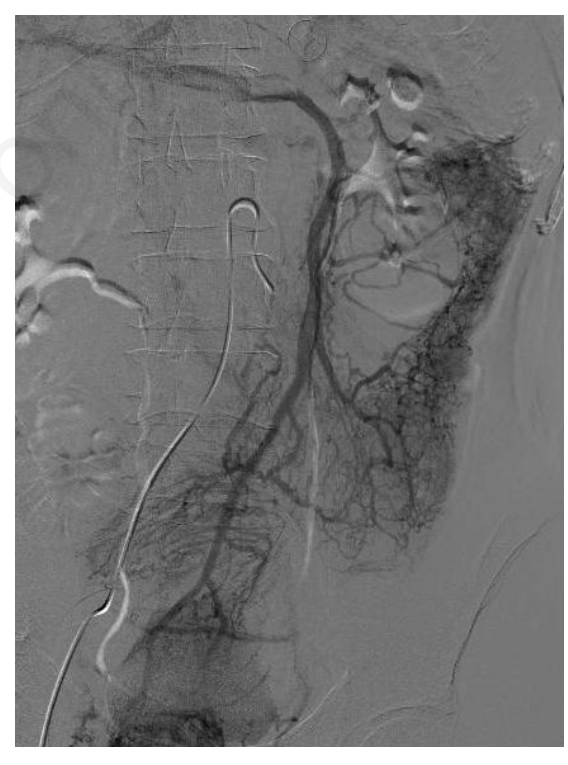

Figure 4. Deep venous thrombosis.

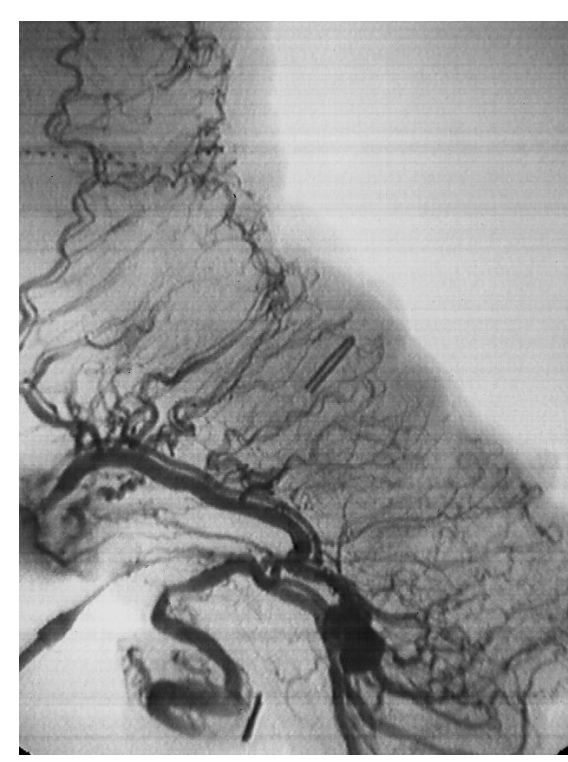

Figure 5. AVM after bowel resection. 


\section{References}

1. Sands BE, Siegel CA. Crohn's disease. In: Feldman M, Friedman L, Brandt L, eds. Sleisenger and Fordtran's gastrointestinal and liver disease. Philadelphia, PA: Saunders; 2010. Chapter 111.

2. Balfour Sartor R. Bacteria in Crohn's disease: mechanism of inflammation and therapeutic implications. J Clin Gastroenterol 2007;41:S37-43.

3. Chiodini RJ, Chamberlin WM, Sarosiek J. Crohn's disease and the mycobacterioses: a quarter century later. Causation or simple association? Crit Rev Microbiol 2012,38:52-93.

4. Frolkis A, Dieleman LA, Barkema H, et al. Environment and the inflammatory bowel diseases. Can J Gastroenterol 2013;27:18-24.
5. Geremia A, Biancheri P, Allan P, et al. Innate and adaptive immunity in inflammatory bowel disease. Autoimmun Rev 2014;13:3-10.

6. Deban L, Correale C, Vetrano S, et al. Multiple pathogenic roles of microvasculature in inflammatory bowel disease: a Jack of all trades. Am J Pathol 2008; 172:1457-66.

7. De Franco A, Di Veronica A, Armuzzi A, et al. Ileal Crohn disease: mural microvascularity quantified with contrast-enhanced US correlates with disease activity. Radiology 2012;262:6808.

8. Morasch MD, Ebaugh JL, Chiou AC, et al. Mesenteric venous thrombosis: a changing clinical entity. J Vasc Surg 2001;34:680-4.

9. Hatoum OA, Spinelli KS, Abu-Hajir M, et al. Mesenteric venous thrombosis in inflammatory bowel disease. J Clin Gastroenterol 2005;39:27-31.

10. Danese S, Papa A, Saibeni S, et al. Inflammation and coagulation in inflammatory bowel disease: the clot thickens. Am J Gastroenterol 2007;102:174-86.

11. Erikson U, Fagerberg S, Krause U, Olding L. Angiographic studies in Crohn's disease and ulcerative colitis. Am J Roentgenol Radium Ther Nucl Med 1970;110:385-92.

12. Brahme F, Hildell J. Angiography in Crohn's disease revisited. Am J Roentgenol 1976;126:941-51.

13. Lee BB, Baumgartner I, Berlien P, et al. Consensus Document of the International Union of Phlebology (IUP): 2013 XVII UIP World Meeting, September 8-13, 2013, Hynes Convention Center, Boston MA. 